\title{
Health-related quality of life in pediatric patients with high-normal blood pressure and primary arterial hypertension
}

A - Study Design, B - Data Colle
Search, G - Funds Collection

Summary Background. Despite the sufficient amount of data characterizings quality of life in adult patients with arterial hypertension and high-normal blood pressure, there is little information concerning the pediatric population.

Objectives. The aim of the presented study was to investigate the association between health-related quality of life (HRQoL) parameters and the amount of increasing arterial blood pressure in children with primary arterial hypertension (PH) and high-normal blood pressure.

Material and methods. We performed a case-control study with an assessment of the impact of BP elevation on HRQoL scores obtained in children 9-17 years old. BP was measured by ambulatory blood pressure monitoring (ABPM). HRQoL was assessed with the PedsQL survey.

Results. The study included 179 participants. Analysis of the impact of high-normal BP or PH on HRQoL parameters found non-linear associations between BP and HRQoL. We found decreased quality of life indicators in children with high-normal BP and first stage PH. The HRQoL parameters of children with stable PH did not differ from those of the control group, with the exception of children with daytime systolic BP higher than $160 \mathrm{~mm} \mathrm{Hg}$, according to the ABPM data.

Conclusions. BP elevation affects quality of life in children with high-normal BP and PH. This relationship is non-linear and consists of the fact that at the beginning of PH formation (systolic BP less than $130 \mathrm{~mm} \mathrm{Hg}$ ), HRQoL parameters are reduced. As BP becomes constantly elevated (systolic BP of 130-160 mm Hg), the HRQoL parameters improve. In children with severe grades of BP elevation, quality of life is low due to adaptation failure.

Key words: children, hypertension, quality of life.

Marushko Y, Hyshchak T, Marushko T, Onufriev O, Zlobynets A, Khomych O, Kostynska N, Moskovenko O. Health-related quality of life in pediatric patients with high-normal blood pressure and primary arterial hypertension. Fam Med Prim Care Rev 2020; 22(4): 291-296, doi: https://doi.org/10.5114/fmpcr.2020.100433.

\section{Background}

The evaluation the health-related quality-of-life (HRQoL) is an important stage of examination of patients with arterial hypertension [1-4]. This indicator, which changes during treatment, allows us to evaluate therapeutic effectiveness, which correlates with a patient's adherence to therapy, including the long-term use of antihypertensive drugs [2,3]. Most studies in adult patients suggest that effective treatment improves quality of life [5]. There are also reports pointing to the fact that the need for long-term antihypertensive therapy for most of patients is associated with decreased quality of life. For example, if the patient was free of symptoms before the onset of therapy (primarily for young patients), he subjectively reveals a decreasing quality of life in the case of prescription of long-term treatment. Furthermore, the reasons for deterioration of quality of life during the treatment of arterial hypertension may be associated with the need for a radical change in lifestyle, restriction for addictions, changes in nutrition and physical activity.

Considering this, a number of large-scale studies have recently been conducted concentrating on factors affecting the quality of life in adult patients with arterial hypertension. Among these factors, gender $[2,6,7]$, presence of concomitant pathology $[7,8]$, educational level, social and economic status [9], age of patients and anxiety-depressive disorders are noted to be significant $[8,10]$.

At the same time, despite a sufficient amount of data characterizing the quality of life in adult patients with arterial hypertension, there is a lack of such information in the pediatric population.

An analysis of literature data showed that most studies on quality of life in children with arterial hypertension were based on the study of office blood pressure (BP) measurement without taking into account ABPM.

It is also relevant to determine HRQoL in children with normal-high BP, because, according to the latest recommendations, such children also need to modify their lifestyle, nutrition and medical follow-up schedule, as well as children with arterial hypertension $[11,12]$. It should be noted that although, according to epidemiological studies, the prevalence of arterial hypertension among children is low (2-4\%), the rate of detection of normal-high BP remains quite high (14.8-16.3\%) $[11,13]$. HRQoL 


\begin{tabular}{|c|c|c|c|c|}
\hline \multirow[t]{2}{*}{ Data } & \multicolumn{4}{|l|}{ Groups } \\
\hline & $\begin{array}{l}\text { 1. Control group, } \\
n=36\end{array}$ & $\begin{array}{l}\text { 2. Patients with high- } \\
\text {-normal BP, } n=64\end{array}$ & $\begin{array}{l}\text { 3. Stage } 1 \text { hypertension, } \\
n=42\end{array}$ & $\begin{array}{l}\text { 4. Stage } 2 \text { hypertension, } \\
n=37\end{array}$ \\
\hline Age, $y$ & $14.0(3.1)$ & $13.97(2.44)$ & $14.02(1.97)$ & $14.73(2.17)$ \\
\hline Male gender, no. (\%) & $50 \%$ & $49.3 \%$ & $52.3 \%$ & $54.1 \%$ \\
\hline Systolic BP, mm Hg & $116.50(3,64)$ & $122.70(6.48)^{* * * 1-2}$ & $135.44(6.33)^{* * * 1-3 ; 2-3}$ & $145.4(7.54)^{* * * 1-4 ; 2-4 ; 3-4}$ \\
\hline Diastolic BP, mm Hg & $63.17(3.92)$ & $65.73(4.66)^{* * 1-2}$ & $69.72(6.48)^{* * * 1-3 ; 2-3}$ & $73.48(7.5) * * * 1-4 ; 2-4 ; * 3-4$ \\
\hline Weight, kg & $56.74(14.69)$ & $59.07(15.24)$ & $65.73(14.95) * * 1-3 ; * 2-3$ & $74.46(15.44) * * * 1-4 ; 2-4 ; * 3-4$ \\
\hline Height, cm & $167.32(14.19)$ & $164.19(12.87)$ & $167.6(10.38)$ & 168.14 (13.99) \\
\hline $\mathrm{BMI}, \mathrm{kg} / \mathrm{m}^{2}$ & $19.93(3.09)$ & $21.63(3.94)^{* 1-2}$ & $23.27(4.33)^{* * * 1-3}$ & $26.19(4.83)^{* * * 1-4 ; 2-4 ; 3-4}$ \\
\hline
\end{tabular}

BMI - body mass index, SD - standard deviation, BP - blood pressure. Significant differences between the groups are indicated by asterisks $\left({ }^{*} p<0.05, * * p<0.01, * * * p<0.001\right)$.

indicators in this category of children could be considered as a criterion for the effectiveness of the prevention of transformation of high-normal BP to arterial hypertension.

\section{Objectives}

The aim of this study was to investigate the association between health-related quality of life (HRQoL) and the rate of blood pressure elevation in children with primary arterial hypertension (PH) and high-normal blood pressure.

\section{Material and methods}

\section{Study design and settings}

This study was a multicenter case-control. The research was carried out from March 2017 to November 2019 in Kiev (Ukraine).

The study involved children 9-17 years old with primary arterial hypertension $(\mathrm{PH})$, high-normal $\mathrm{BP}$, without BP elevation (control subjects) and without any history of cardiovascular disease.

\section{Participants}

The study involved 179 patients. The demographic information, including age, gender, body mass index and stage of $\mathrm{PH}$, is shown in Table 1.

To exclude the influence of age and gender, the examined groups were composed in such a way that they did not statistically differ by these criteria.

The diagnosis "primary arterial hypertension" (PH) was established for all children for the first time, and none had received antihypertensive therapy in the past. The study did not include children with secondary arterial hypertension.

\section{Variables}

BP was classified according to the European Society of Hypertension guidelines for the management of high $\mathrm{BP}$ in children and adolescents as normotensive ( $\mathrm{BP}<90^{\text {th }}$ percentile), high-normal $\mathrm{BP}$ ( $\mathrm{BP} \geq 90^{\text {th }}$ and $<95^{\text {th }}$ percentile) or hypertensive (BP $\geq 95^{\text {th }}$ percentile) $[11,12]$.

\section{Data sources}

$B P$ was measured both during the visit and by ABPM. ABPM was conducted every 3 months after the baseline using the "ABM-04" device ("Meditech" Hungary). BP measurements were collected every 15 minutes during the day and 30 minutes during the night. The patient and their family kept a diary recording during the wake-up period and sleeping period and included recordings about any medications given while moni- toring [14]. A systolic or diastolic BP load $>80 \%$ was defined as second stage arterial hypertension, a systolic or diastolic BP load of $51-80 \%$ was defined as first stage arterial hypertension, and a systolic or diastolic BP load of $11-50 \%$ was determined as high-normal BP $[11,15]$.

We used the Ukrainian version of the pediatric scale for assessing the quality of life (PedsQL) 4.0 [16-18], given the fact that this test showed good reproducibility, reliability and validity of the results in previous studies [18-20]. HRQoL was measured during the baseline visit and follow-up visits at 3-month intervals.

According to the questionnaire, physical (8 points), emotional (5 points), social (5 points) and school functioning of respondents ( 5 points) were evaluated in a range from 0 to 100 points, with higher scores suggesting a better HRQoL. The Kolmogorov-Smirnov test revealed all the scores of this scale to be within normal ranges.

Two additional final parameters were calculated: Total Score and the summary scale of psychosocial health (average score combining the data of emotional, social and school functioning).

\section{Statistical methods}

For statistical analysis, we used IBM SPSS Statistics software (version 20) as a Microsoft Windows 10 application.

We used $t$-test of independent samples (Student $t$-test) for comparing the average values between patients with elevated BP and the control group. A $p$-value less than $0.05(p<0.05)$ was considered to be statistically significant. We also used correlation analysis with the determination of the correlation ratio $(\eta)$ for nonlinear dependencies and the correlation coefficient $(r)$ for linear dependencies. A correlation coefficient of 0.5 or above was considered strong, 0.35-0.5 - moderate, 0.2-0.34 - poor, and below 0.2 - absent.

\section{Ethical consideration}

The research was carried out in accordance with ethical principles of scientific research and the declaration of Helsin$\mathrm{ki}$ and was approved by the ethics committee of the National Medical University (protocol 22, 3.03.2017).

\section{Results}

Data concerning BP and HRQoL was available for 179 subjects. Based on the results of ABPM, 4 comparison groups were formed (Table 2).

The lowest quality of life indexes (Total Score) were found in children with high-normal BP ( $p<0.01$ compared to the control group) and in those with $\mathrm{PH}$ of the first degree ( $p<0.05$ compared with the control group). The Total Score in children with second stage $\mathrm{PH}$ did not significantly differ from the data of the control group patients (Table 3). 


\begin{tabular}{|l|l|l|l|l|}
\hline \multirow{2}{*}{ Table 2. ABPM results (mean (SD)) } \\
\cline { 2 - 5 } & $\begin{array}{l}\text { Groups } \\
\text { 1. Control group } \\
n=36\end{array}$ & $\begin{array}{l}\text { 2. Patients with high- } \\
- \text { normal BP } \\
n=64\end{array}$ & $\begin{array}{l}\text { 3. Stage 1 hypertension } \\
n=42\end{array}$ & $\begin{array}{l}\text { 4. Stage 2 hypertension } \\
n=37\end{array}$ \\
\hline Daytime SBP, mm Hg & $118.72(4.22)$ & $124.46(5.84)^{* * * 1-2}$ & $136.05(6.11)^{* * * 1-3 ; 2-3}$ & $148.07(7.83)^{* * * 1-4 ; 2-4 ; 3-4}$ \\
\hline Daytime DBP, mm Hg & $65.29(3.86)$ & $68.29(4.37)^{* * * 1-2}$ & $72.81(6.0)^{* * * 1-3 ; 2-3}$ & $77.8(8.83)^{* * * 1-4 ; 2-4 ; * * 3-4}$ \\
\hline Nighttime SBP, mm Hg & $109.64(6.56)$ & $117.77(9.79)^{* * * 1-2}$ & $128.27(11.41)^{* * * 1-3 ; 2-3}$ & $143.48(13.38)^{* * * 1-4 ; 2-4 ; 3-4}$ \\
\hline Nighttime DBP, mm Hg & $55.37(6.18)$ & $61.32(7.15)^{* * * 1-2}$ & $63.12(5.35)^{* * * 1-3}$ & $72.06(11.15)^{* * * 1-4 ; 2-4 ; 3-4}$ \\
\hline SBP load, \% & $13.16(7.29)$ & $29.89(11.36)^{* * * 1-2}$ & $64.36(8.93)^{* * * 1-3 ; 2-3}$ & $90.11(5.25)^{* * * 1-4 ; 2-4 ; 3-4}$ \\
\hline DBP load, \% & $2.59(4.13)$ & $9.34(7.81)^{* * * 1-2}$ & $17.35(14.69)^{* * * 1-3 ; * * 2-3}$ & $31.91(27.58)^{* * * 1-4 ; 2-4 ; * * 3-4}$ \\
\hline SBP dipping, \% & $7.41(5.48)$ & $5.33(6.66)$ & $5.71(6.68)$ & $3.09(7.49)^{* * 1-4}$ \\
\hline DBP dipping, \% & $14.95(8.8)$ & $10.22(8.48)^{* 1-2}$ & $12.12(6.89)$ & $7.67(8.08)^{* * * 1-4}$ \\
\hline
\end{tabular}

SBP - systolic blood pressure, DBP - diastolic blood pressure. Significant differences between the groups are indicated by asterisks $(* p<0.05$, $\left.{ }^{* *} p<0.01,{ }^{* * *} p<0.001\right)$.

\begin{tabular}{|l|l|l|l|l|}
\hline \multirow{2}{*}{ Table 3. HRQoL in children with PH compared with children with high-normal BP and children in the control group (Mean (SD)) } \\
\hline & \begin{tabular}{l} 
Groups \\
Data \\
\cline { 2 - 5 }
\end{tabular} 1. Control group & $\begin{array}{l}\text { 2. Patients with high- } \\
- \text {-normal BP } \\
n=64\end{array}$ & $\begin{array}{l}\text { 3. Stage } 1 \text { hypertension } \\
n=42\end{array}$ & $\begin{array}{l}\text { 4. Stage } 2 \text { hypertension } \\
n=37\end{array}$ \\
\hline Total Score & $79.05(12.25)$ & $71.37(12.44)^{* * 1-2}$ & $73.24(12.45)^{* 1-3}$ & $74.98(12,37)$ \\
\hline Psychosocial health & $77.73(9.94)$ & $68.72(11.71)^{* * * 1-2}$ & $72.82(11.48)^{* 1-3}$ & $72.51(12.02)^{* 1-4}$ \\
\hline Physical functioning & $82.66(11.83)$ & $74.02(15.9)^{* * 1-2}$ & $74.40(21.19)^{* 1-3}$ & $77.45(14.79)$ \\
\hline Emotional functioning & $74.17(12.39)$ & $62.89(16.9)^{* * * 1-2}$ & $64.39(16.81)^{* * 1-3}$ & $64.14(14.92)^{* * 1-4}$ \\
\hline Social functioning & $86.25(12.89)$ & $81.95(13.73)$ & $86.9(14.27)$ & $85.41(12.16)$ \\
\hline School functioning & $72.78(13.65)$ & $61.33(15.77)^{* * * 1-2}$ & $67.2(18.89)$ & $67.97(17.26)$ \\
\hline
\end{tabular}

Significant differences between the groups are indicated by asterisks ( $\left.{ }^{*} p<0.05, * * p<0.01, * * * p<0.001\right)$.

The lowest indexes from the questionnaire data were indicators of psychosocial health, which were reduced compared with the control group in all categories of children. Physical health according to the questionnaire was lower in children with stable first stage $\mathrm{PH}$ and high-normal BP compared to the control group. Although Physical Functioning in patients with second stage $\mathrm{PH}$ tended to decrease, it did not differ significantly from the same parameter of the control group. Social Functioning in our study in all groups did not show any large differences.

Correlation analysis showed a poor positive linear correlation between some questionnaire data parameters and level of nighttime systolic BP (SBP) according to ABPM data (Table 4).

\begin{tabular}{|c|c|c|c|}
\hline Data & Total & Physical & Psychosocial \\
\hline Daytime SBP & $0.40 / \mathrm{NS}$ & $0.38 / \mathrm{NS}$ & $0.35 / \mathrm{NS}$ \\
\hline Daytime DBP & $0.28 / \mathrm{NS}$ & $0.25 / \mathrm{NS}$ & $0.31 / \mathrm{NS}$ \\
\hline Nighttime SBP & $0.40 / 0.24$ & $0.43 / 0.28$ & $0.38 / \mathrm{NS}$ \\
\hline Nighttime DBP & $0.31 / \mathrm{NS}$ & $0.30 / \mathrm{NS}$ & $0.31 / \mathrm{NS}$ \\
\hline SBP dipping & $0.21 /-0.2$ & $0.28 /-0.25$ & NS/NS \\
\hline DBP dipping & $0.28 / \mathrm{NS}$ & $0.31 /-0.22$ & $0.26 / \mathrm{NS}$ \\
\hline Age & $\mathrm{NS} / \mathrm{NS}$ & NS/NS & NS/NS \\
\hline BMI & NS/NS & NS/NS & NS/NS \\
\hline
\end{tabular}

SBP - systolic blood pressure, DBP - diastolic blood pressure. BMI - body mass index, $\eta$-correlation relation, $r$ is the correlation coefficient. All noted as statistically significant with $p<0.05$, others non-significant (NS).

There were no direct statistically significant correlations between HRQoL and level of diastolic BP (DBP). At the same time, a fairly strong nonlinear correlation between parameters was revealed. Moderate effect sizes $(0.35-0.43)$ were found in relation to total, physical, psychosocial functioning and SBP level. Nonlinear correlation indexes ranging from 0.25 to 0.31 were characteristic of DBP with respect to individual survey indicators.

It should be noted that although the study groups were different in terms of body mass index, the correlation between $\mathrm{HRQ}$ oL and body mass index was not significant. A statistically significant correlation between HRQoL and the age of children was not observed in our study.

Figure 1 graphically shows the patterns of Total Score and BP according to ABPM data.

As can be seen from the trend line, patients with daytime SBP below $130 \mathrm{~mm} \mathrm{Hg}$ had a lower Total Score in comparison with children with daytime SBP at a level of $130-160 \mathrm{~mm} \mathrm{Hg}$. Children with a daytime SBP within the ranges of $140-160 \mathrm{~mm}$ $\mathrm{Hg}$, as a rule, considered their $\mathrm{HRQ}$ oL to include the maximal possible score. With a further increase in daytime SBP (more than $160 \mathrm{~mm} \mathrm{Hg}$ ), the Total Score decreased sharply.

Since the increase in diastolic BP was characteristic only for second stage arterial hypertension, the correlation with HRQoL was less noticeable. However, a tendency towards lower HRQoL parameters in children with high DBP was observed (Figure 1 $B, D)$.

When assessing the HRQoL indexes in children with varying degrees of a nighttime decrease in BP, we found that an insufficient degree of a nightly decrease in BP did not negatively affect the HRQoL of children with PH. This was confirmed by the results of the correlation analysis presented in Table 4 and in Figure 2. 

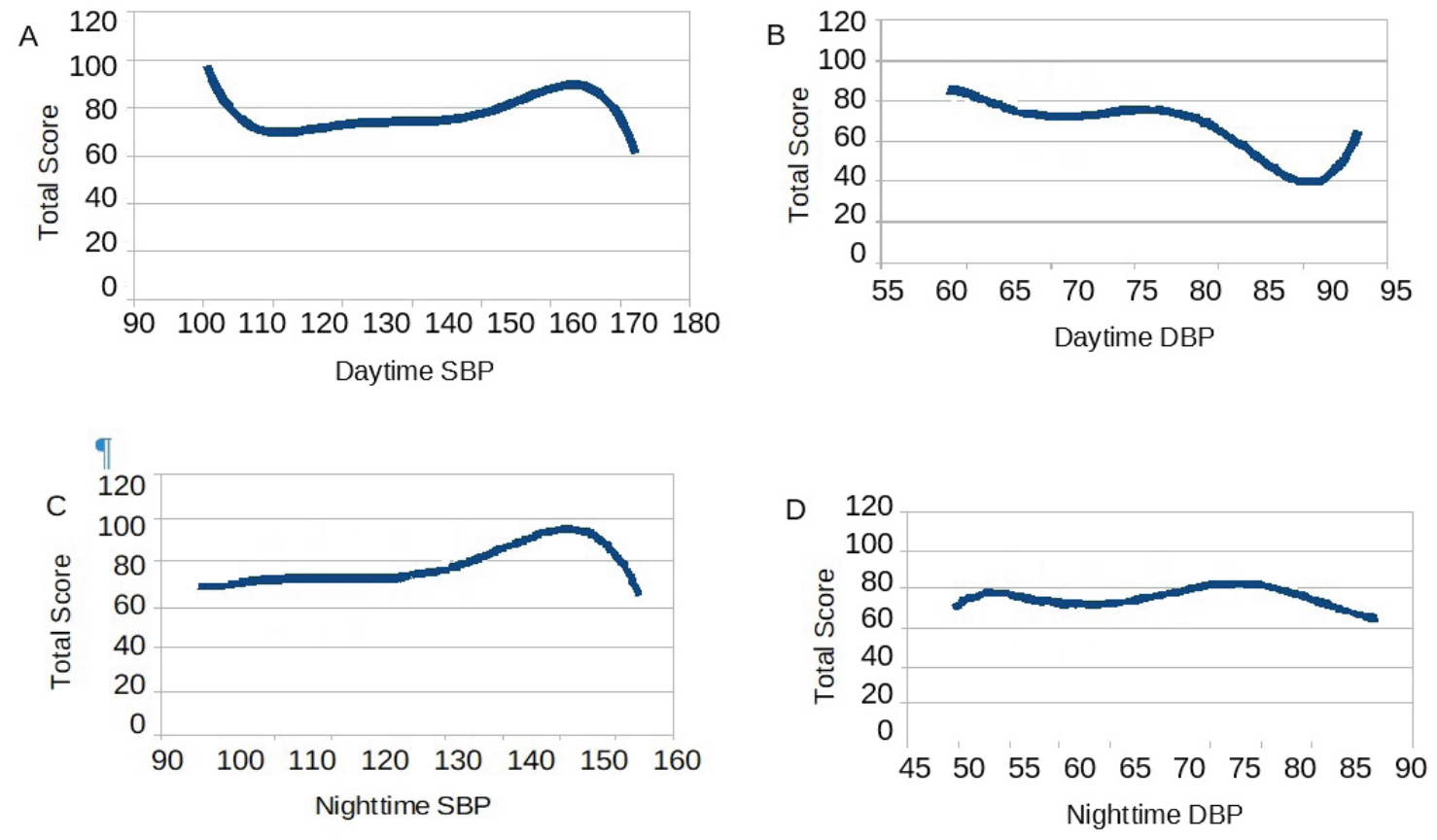

Figure 1. Trend line of Total Score versus day (A, B), night (C, D), systolic (SBP) and diastolic (DBP) blood pressure

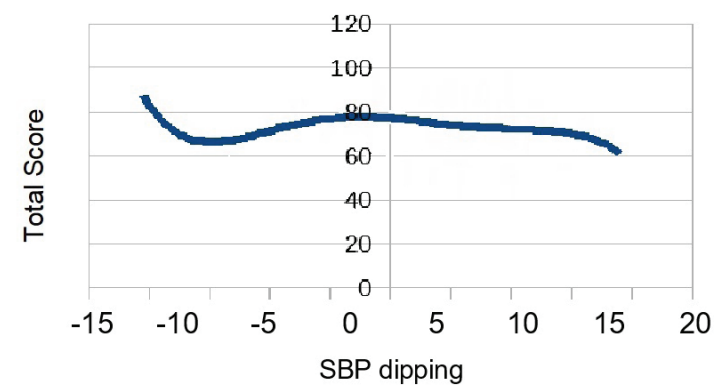

Figure 2. Trend line of the Total Score versus the degree of nighttime decline in SBP

\section{Discussion}

According to the objectives of the study, we investigated the associations between health-related quality of life (HRQoL) and rate of blood pressure elevation in children with primary arterial hypertension (PH) and high-normal blood pressure. In children with high-normal blood pressure and first stage hypertension, quality of life indicators were lower compared to the control group and children with second stage hypertension. Moreover, the relationship between BP and HRQoL was statistically significant and non-linear.

Our results from the questioning of children with normal BP in general terms are consistent with data from other studies. The Total Score HRQoL for healthy schoolchildren, according to different authors, ranges from 72.7 to 86.9 points [21-24]. In our study, the Total Score HRQoL in the control group was 79.05 [12.25].

According to research conducted in Slovenia [23], children with normal BP had a Total Score HRQoL of 84.66 [11.00] points, and children with PH had a Total Score HRQoL 7of 7.72 [14.57] points. This work did not take into account the degree of BP increase. The article does not show the BP parameters of the examined children. However, it noticed that, for most patients, a single modification of life style was a sufficient treatment option, which suggests that the degree of increase in BP was negligible. In this case, the results obtained in Slovenia may be similar to those that we received from children with first stage $\mathrm{PH}$ in terms of HRQoL values. In addition, unlike our data, in the presented study, children with both primary and secondary hypertension were included. The presence and severity of the underlying disease could significantly affect the results of the survey. The authors also indicated that the study did not take into account comorbidities, and moreover, adolescents were not aware of arterial hypertension.

If we would not take into account the difference in the absolute indicators of HRQoL in our study and the study presented above, the identified trends can be considered as similar. In particular, a fairly high level of physical functioning in children with hypertension compared with psychosocial was common. As in the Slovenian study, our data also suggests that the smallest number of points in children with $\mathrm{PH}$ can be obtained via the Emotional Functioning scale. Increased BP did not affect the level of Social Functioning in both studies.

The revealed differences are possibly related to the age of patients. The Slovenian study included children from 6 to 15 years old, meanwhile, our study included patients from 9 to 17 years old.

In contrast, data reported by Petek et al. [24] showed that high BP was associated with good HRQoL parameters in children and adolescents [25], including those with high BP due to chronic kidney disease [26].

A study by Berendes et al. [25] included 7697 participants between 11 and 17 years of age. The central finding of this in- 
vestigation was that adolescents with elevated BP reported significantly better HRQoL parameters and lower levels of distress. The total score in children with arterial hypertension was approx. 73.4 [10.0] points and was significantly higher compared to children with normal BP (72.5 [10.4] points, $p=0.006)$. "Physical well-being" totaled 72.7 [15.5] points versus 70.4 [16.6] points, $p=0.001$, respectively.

The authors pointed out that the correlation they found between high BP, well-being and low levels of distress can be explained by the lack of concomitant physical comorbidity, lack of understanding of hypertension and a bi-directional relationship with suppressed emotions. The authors point out that increasing BP in children and adolescents can be a potential stress buffer. We completely agree with this interpretation of the causes of normal HRQoL parameters in children with high $\mathrm{BP}$, since, in our previous studies, we also obtained evidence of the presence of certain adaptation phases in $\mathrm{PH}$ pathogenesis closely related to stress.

In a study by Wong et al. [26], BP was measured both by office measurements and by ABPM, which are the same methods we used. The goal of this study was to determine if elevated $\mathrm{BP}$ and/or antihypertensive medication usage had a negative impact on HRQoL parameters in children with chronic kidney disease. In contrast to our research, the study involved children with secondary arterial hypertension in the presence of chronic kidney disease. The mean total score in hypertensive patients was $79[68,87]$ points, and in normotensive patients - 82 [69, $90]$ points, $p=0.14$. Physical functioning was at a fairly high level (about 84 points) regardless of BP. The differences between normotensive and hypertensive patients only included school functioning, which was significantly lower in hypertensive patients $(65[55,80]$ versus $75[60,85]$ points, $p=0.007)$. In our study, school functioning was also reduced more than other parameters, significantly affecting the total score of psychosocial functioning.

Statistical analysis in this study also suggested the construction of longitudinal median regression models, though these models did not find a significant relationship between the BP indicators and $\mathrm{HRQ}$ oL parameters.

In addition, the use of antihypertensive drugs was not associated with a decrease in the HRQoL parameters of children.

In our study, the effect of antihypertensive therapy on HRQoL parameters was not studied. We plan to continue research in this direction. In the near future, we also plan to provide data on gender differences in HRQoL indicators for different stages of $\mathrm{PH}$.
A number of other studies also examined the correlation between blood pressure and HRQoL parameters in children [27, 28]. One of them [27] was attended by 48 children $9-10$ years old with normal BP and prehypertension. In another [28], there were 113 children 7-18 years old with chronic kidney disease. Among them there were 46 children with normal blood pressure, 22 with prehypertension and 45 with hypertension. In both studies, hypertension was based on office blood pressure measurements. Direct correlation between office blood pressure and quality of life indicators were absent.

Our study had several limitations. We did not have the opportunity to assess the duration of the disease until the time of diagnosis, because many patients having episodes of high BP did not ask for medical help. Children with high-normal blood pressure lacked documented data on the duration of elevated BP.

Rather low HRQoL parameters were revealed in children with high-normal $\mathrm{BP}$, which allows one to consider this category of patients as a risk group for the progression of high BP into $\mathrm{PH}$. We believe that, along with the recommendations that exist today, which provide a modification of life in children with high-normal BP, this category of patients needs more intensive treatment aimed at influencing patient perception of stress factors. We believe that stabilization of arterial hypertension should be considered as an adaptation of the body to fluctuations in BP arising under the influence of various stress factors. In this regard, we can recommend an HRQoL test in children with high-normal BP as a method of identifying risk groups for the progression of $\mathrm{PH}$.

\section{Conclusions}

The analysis of HRQoL parameters in children and adolescents 9-17 years old with PH or high-normal BP shows that BP moderately affects quality of life in this category of children and adolescents. This correlation is predominantly non-linear in nature and consists of the fact that at the onset of arterial hypertension, HRQoL parameters are significantly reduced (in children with daytime SBP less than $130 \mathrm{~mm} \mathrm{Hg}$ ). As BP become constantly elevated (in children with daytime SBP of $130-160 \mathrm{~mm} \mathrm{Hg}$ ), the HRQoL parameters improve. In children with extremely high BP levels, the HRQoL parameters are low due to a failure in adaptation. This data should be taken into account when evaluating the effectiveness of treatment of children and adolescents with $\mathrm{PH}$ and when monitoring children with high-normal BP.

Children with significant changes in $\mathrm{HRQ}$ oL require additional visits to primary care physicians and further psychological and pharmacological correction.

Source of funding: This work was funded from the authors' own resources.

Conflicts of interest: The authors declare no conflicts of interest.

\section{References}

1. Soutello AL, Rodrigues RC, Jannuzzi FF, et al. Quality of Life on arterial hypertension: validity of known groups of MINICHAL. Arq Bras Cardiol 2015; 104(4): 299-307, doi: 10.5935/abc.20150009.

2. Trevisol DJ, Moreira LB, Kerkhoff A, et al. Health-related quality of life and hypertension: a systematic review and meta-analysis of observational studies. J Hypertens 2011; 29(2): 179-188.

3. Amer M, Rahman N, Nazir SR, et al. Impact of pharmacist's intervention on disease related knowledge, medication adherence, HRQoL and control of blood pressure among hypertensive patients. Pak J Pharm Sci 2018; 31(6): 2607-2616.

4. Uzark K, King E, Spicer R, et al. The clinical utility of health-related quality of life assessment in pediatric cardiology outpatient practice. Congenit Heart Dis 2013; 8: 211-218, doi: 10.1111/chd.12002.

5. Schmieder RE, Jumar A, Fronk EM, et al. Quality of life and emotional impact of a fixed-dose combination of antihypertensive drugs in patients with uncontrolled hypertension. J Clin Hypertens (Greenwich) 2017; 19(2): 126-134, doi: 10.1111/jch.12936.

6. Reenen M van, Janssen B. EQ-5D-5L User Guide - Basic information on how to use the EQ-5D-5L instrument. Version 2.1. 2015. Available from URL: http://www.euroqol.org/fileadmin/user_upload/ Documenten/PDF/Folders_Flyers/EQ-5D-5L_UserGuide_2015.pdf.

7. Lee MH, So ES. Impact of hypertension-related comorbidity on health-related quality of life: a population-based survey in South Korea. Asia Pac J Public Health 2012; 24(5): 753-763.

8. Wang R, Zhaoa Y, He X, et al. Impact of hypertension on health-related quality of life in a population-based study in Shanghai, China. Public Health 2009; 123(8): 534-539.

9. Galenkamp H, Oers HAM van, Kunst AE, et al. Is quality of life impairment associated with chronic diseases dependent on educational level? Eur J Public Health 2019; 18, doi: 10.1093/eurpub/cky276. 
10. Theodorou M, Kaitelidou D, Galanis P, et al. Quality of life measurement in patients with hypertension in Cyprus. Hell J Cardiol 2011; 52: 407-415.

11. Flynn JT, Kaelber DC, Baker-Smith CM, et al. Clinical practice guideline for screening and management of high blood pressure in children and adolescents. Pediatrics 2017; 140(3): e20171904, doi: 10.1542/peds.2017-1904.

12. Lurbea E, Agabiti-Roseic E, Cruickshankd JK, et al. 2016 European Society of Hypertension guidelines for the management of high blood pressure in children and adolescents. J Hypertens 2016; 34(10): 1887-1920, doi: 10.1097/HJH.0000000000001039.

13. Bell CS, Samuel JP, Samuels JA. Prevalence of hypertension in children. Hypertension 2019; 73(1): 148-152, doi: 10.1161/HYPERTENSION AHA.118.11673.

14. Samuels J, Ng D, Flynn JT, et al. Chronic Kidney Disease in Children Study G. Ambulatory blood pressure patterns in children with chronic kidney disease. Hypertension 2012; 60: 43-50.

15. The Task Force for the management of arterial hypertension of the European Society of Cardiology (ESC) and the European Society of Hypertension (ESH). Eur Heart J 2018; 39(33): 3021-3104, doi: 10.1093/eurheartj/ehy339.

16. Varni JW, Seid M, Kurtin PS. PedsQL 4.0: reliability and validity of the Pediatric Quality of Life Inventory version 4.0 generic core scales in healthy and patient populations. Med Care 2001; 39: 800-812.

17. Varni JW, Seid M, Rode CA. The PedsQL: measurement model for the pediatric quality of life inventory. Med Care 1999; 37: 126-139.

18. Hullmann SE, Ryan JL, Ramsey RR, et al. Measures of general pediatric quality of life: child health questionnaire (CHQ), DISABKIDS chronic generic measure (DCGM), KINDL-R, pediatric quality of life inventory (PedsQL) 4.0 generic Core scales, and quality of my life questionnaire (QoML). Arthritis Care Res 2011; 63(Suppl. 1): S420-S430, doi: 10.1002/acr.20637.

19. Eiser C, Morse R. A review of measures of quality of life for children with chronic illness. Arch Dis Child 2001; 84: 205-211, doi: 10.1136/adc.84.3.205.

20. Varni JW, Limbers CA. The pediatric quality of life inventory: measuring pediatric health-related quality of life from the perspective of children and their parents. Pediatr Clin N Am 2009; 56: 843-863, doi: 10.1016/j.pcl.2009.05.016.

21. Wu XY, Han LH, Zhang JH, et al. The influence of physical activity, sedentary behavior on health-related quality of life among the general population of children and adolescents: a systematic review. PLOS ONE 2017; 12(11): e0187668, doi: 10.1371/journal.pone.0187668.

22. Hovsepian S, Qorbani M, Motlagh ME, et al. Association of obesity and health related quality of life in Iranian children and adolescents: the Weight Disorders Survey of the CASPIAN-IV study. J Pediatr Endocrinol Metab 2017; 30(9): 923-929, doi: 10.1515/jpem-2016-0402.

23. Ha NT, Trang DTH, Ha LTT. Is obesity associated with decreased health-related quality of life in school-age children? - Results from a survey in Vietnam. AIMS Public Health 2018; 5(4): 338-351, doi: 10.3934/publichealth.2018.4.338.

24. Petek T, Hertiš T, Marčun Varda N. Health-related quality of life in paediatric arterial hypertension: a cross-sectional study. BMC Pediatr 2018; 18(1): 146, doi: 10.1186/s12887-018-1120-0.

25. Berendes A, Meyer T, Hulpke-Wette M, et al. Association of elevated blood pressure with low distress and good quality of life: results from the nationwide representative German health interview and examination survey for children and adolescents. Psychosom Med 2013; 75: 422-428, doi: 10.1097/PSY.0b013e31828ef0c2.

26. Wong C, Gerson A, Hooper S, et al. Effect of elevated blood pressure on quality of life in children with chronic kidney disease. Pediatr Nephrol 2016; 31(7): 1129-1136, doi: 10.1007/s00467-015-3262-8.

27. Smith E. Blood pressure and quality of life in youth enrolled in a culinary skills, family mealtime and physical activity program: Pilot study icook 4-h. (2014). Graduate Theses, Dissertations, and Problem Reports. 128. Available from URL: https://researchrepository. wvu.edu/etd/128.

28. Hsu CN, Lin HW, Pickard A, et al. EQ-5D-Y for the assessment of health-related quality of life among Taiwanese youth with mild-tomoderate chronic kidney disease. Int J Qual Health Care 2018; 30(4): 298-305, doi: 10.1093/intqhc/mzy011.

Tables: 4

Figures: 2

References: 28

Received: 20.12.2019

Reviewed: 5.02.2020

Accepted: 11.05 .2020

Address for correspondence:

Olha Khomych, PhD, Assoc. Prof.

Department of Pediatrics of Postgraduate Education

O.O. Bohomolets Medical University

str. Vasilenko 23B, apartment 129, Kiev

03124, Ukraine

Tel.: +38 0932874976

E-mail:khomychov@gmail.com 